\title{
The Chloride Intracellular Channel Protein CLIC5 Is Expressed at High Levels in Hair Cell Stereocilia and Is Essential for Normal Inner Ear Function
}

\author{
Leona H. Gagnon, ${ }^{1}$ Chantal M. Longo-Guess, ${ }^{1}$ Mark Berryman, ${ }^{2}$ Jung-Bum Shin, ${ }^{3}$ Katherine W. Saylor, ${ }^{1}$ Heping Yu, ${ }^{1}$ \\ Peter G. Gillespie, ${ }^{3}$ and Kenneth R. Johnson ${ }^{1}$ \\ ${ }^{1}$ The Jackson Laboratory, Bar Harbor, Maine 04609, ${ }^{2}$ Ohio University College of Osteopathic Medicine, Athens, Ohio 45701, and ${ }^{3}$ Oregon Hearing Research \\ Center and Vollum Institute, Portland, Oregon 97239
}

\begin{abstract}
Although CLIC5 is a member of the chloride intracellular channel protein family, its association with actin-based cytoskeletal structures suggests that it may play an important role in their assembly or maintenance. Mice homozygous for a new spontaneous recessive mutation of the Clic5 gene, named jitterbug ( $j b g$ ), exhibit impaired hearing and vestibular dysfunction. The $j b g$ mutation is a $97 \mathrm{bp}$ intragenic deletion that causes skipping of exon 5, which creates a translational frame shift and premature stop codon. Western blot and immunohistochemistry results confirmed the predicted absence of CLIC5 protein in tissues of $j b g / j b g$ mutant mice. Histological analysis of mutant inner ears revealed dysmorphic stereocilia and progressive hair cell degeneration. In wild-type mice, CLIC5-specific immunofluorescence was detected in stereocilia of both cochlear and vestibular hair cells and also along the apical surface of Kolliker's organ during cochlear development. Refined immunolocalization in rat and chicken vestibular hair cells showed that CLIC5 is limited to the basal region of the hair bundle, similar to the known location of radixin. Radixin immunostaining appeared reduced in hair bundles of $j b g$ mutant mice. By mass spectrometry and immunoblotting, CLIC5 was shown to be expressed at high levels in stereocilia of the chicken utricle, in an approximate 1:1 molar ratio with radixin. These results suggest that CLIC5 associates with radixin in hair cell stereocilia and may help form or stabilize connections between the plasma membrane and the filamentous actin core.
\end{abstract}

Key words: CLIC5; mouse mutation; deafness; inner ear; hair cell; stereocilia

\section{Introduction}

The specialized hair cells of the inner ear function as mechanoreceptors for hearing and balance. They are characterized by giant microvilli, called stereocilia, that project from their apical surfaces (Frolenkov et al., 2004). These highly sensitive organelles contain mechanosensitive ion channels that are able to detect rapid, sub-nanometer deflections in response to sound waves or head movements (LeMasurier and Gillespie, 2005). The stereocilia of each hair cell are interconnected by extracellular links to form a hair bundle. Although the hair bundle is crucial for both auditory and vestibular function, its small size and the limited number of hair cells make its molecular dissection by traditional

\footnotetext{
Received May 22, 2006; revised July 25, 2006; accepted Aug. 20, 2006.

This work was supported by National Institutes of Health Grants DC04301 (K.R.J.), DC006097 (P.G.G), and DC002368 (P.G.G.) from the National Institute on Deafness and Other Communication Disorders and by Grant RR01183 from the National Center for Research Resources. M.B. was supported by the Ohio University Office of Research and Sponsored Programs. K.W.S. was supported by the National Science Foundation, the Barbara H. Sanford Endowment, and the Horace W. Goldsmith Foundation. We thank Amy Kiernan and David Bergstrom for providing helpful comments on this manuscript. We also thank Serrena Lovley for the initial discovery of the mutant mice, Sandra Gray for mouse colony management, Priscilla Jewett for histological preparations, Peter Finger for scanning electron microscopy assistance, and Cory Bystrom and Debra McMillen (Oregon Health and Science University Proteomics Shared Resource, Portland, OR) for mass spectrometry analysis.

Correspondence should be addressed to Kenneth R. Johnson, The Jackson Laboratory, 600 Main Street, Bar Harbor, ME 04609. E-mail: ken.johnson@jax.org.

DOI:10.1523/JNEUROSCI.2166-06.2006

Copyright $\odot 2006$ Society for Neuroscience ～0270-6474/06/2610188-11\$15.00/0
}

biochemical methods difficult. Genetic studies of human and mouse deafness mutations, however, have successfully led to the discovery of several proteins that contribute to the development and maintenance of hair cell stereocilia (Petit, 2006). More recently, a proteomic approach, which couples high-purity isolation with mass spectrometry, has been developed to identify and quantify hair bundle proteins (Gillespie and Hudspeth, 1991; Domon and Aebersold, 2006). Here, we describe how these two complementary approaches were used to identify and characterize a previously unknown constituent of hair cell stereocilia, the chloride intracellular channel 5 (CLIC5) protein. By genetic mapping and mutation scanning, we identified Clic5 as the gene responsible for a newly discovered mouse deafness mutant named jitterbug ( $j b g$ ) and localized the CLIC5 protein to hair cell stereocilia. Independently, by mass spectrometric analysis, we confirmed the high abundance of CLIC5 in isolated hair bundles of the chicken utricle.

CLIC5 was initially isolated from microvilli of placental epithelial cells and identified as a component of a cytoskeletal complex containing actin and ezrin, suggesting a possible role in the assembly or maintenance of actin-based structures at the cell cortex (Berryman and Bretscher, 2000). CLIC5 is a member of the chloride intracellular channel family of proteins, which share $47-76 \%$ overall amino acid sequence identity in their C-terminal $\sim 220$ amino acids (Cromer et al., 2002; Friedli et al., 2003). The 
structure of CLICs is unusual compared with typical ion channel proteins; CLICs are relatively small proteins that lack an $\mathrm{N}$-terminal signal sequence and contain only a single putative transmembrane domain. Despite their name, the molecular function and physiological relevance of CLIC proteins is poorly understood. Although some purified CLIC proteins appear to form chloride channels in artificial membranes (Tulk et al., 2002; Warton et al., 2002; Littler et al., 2005), whether they function as chloride channels in vivo is still an open question (Friedli et al., 2003; Griffon et al., 2003; Berryman et al., 2004). Although CLIC proteins can definitely localize to membranes (Nishizawa et al., 2000; Berry and Hobert, 2006), there is conflicting data on their proposed membrane topology (Tonini et al., 2000; Proutski et al., 2002; Berryman et al., 2004), and it is not yet clear whether they associate as integral or peripheral membrane proteins. CLICs also exist as soluble cytosolic proteins and are related to glutathione S-transferases (Dulhunty et al., 2001; Harrop et al., 2001). Because evidence for CLIC-mediated chloride transport in vivo is weak, it is likely that CLIC proteins have alternate functions that are distinct from their proposed roles as chloride channels.

Although loss-of-function studies have been conducted in Caenorhabditis elegans (Berry et al., 2003) and in cultured cells (Suh et al., 2005), until now no animal models have been available that directly address the role of specific CLIC members in the more complex context of vertebrate physiology. Here, we present our analyses of the $j b g$ mutation of Clic5 in mice and demonstrate an important role for CLIC5 in inner ear function. Our localization of CLIC5 to the hair bundle and our evidence supporting its association with radixin suggest a role for this protein in facilitating the linkage of actin filaments with the plasma membrane.

\section{Materials and Methods}

Experimental animals. All mice in this study were obtained from research or production colonies at The Jackson Laboratory (Bar Harbor, ME). The $j b g$ mutation arose spontaneously at The Jackson Laboratory in a $\mathrm{C} 3 \mathrm{H} / \mathrm{HeJ}$ production colony in 1999, and the $j b g$ mutant colony has been maintained by sibling mating. Mutant mice $(j b g / j b g)$ are identified by their overt circling and head-bobbing behavior.

All procedures were approved by The Jackson Laboratory Animal Care and Use Committee.

Auditory-evoked brainstem response. Hearing in mice was assessed by auditory-evoked brainstem response (ABR) thresholds, as described previously (Zheng et al., 1999). Briefly, mice were anesthetized and body temperature was maintained at $37-38^{\circ} \mathrm{C}$ by placing them on an isothermal pad in a sound-attenuating chamber. Subdermal needles were used as electrodes, inserted at the vertex and ventrolaterally to each ear. Stimulus presentation, $\mathrm{ABR}$ acquisition, equipment control, and data management were coordinated using the computerized Intelligent Hearing Systems (IHS) (Intelligent Hearing Systems, Miami, FL). A pair of highfrequency transducers was coupled with the IHS system to generate specific acoustic stimuli. Clicks and 8,16 , and $32 \mathrm{kHz}$ tone bursts were channeled through plastic tubes into the animal's ear canals. The amplified brainstem responses were averaged by a computer and displayed on the computer screen. Auditory thresholds were obtained for each stimulus by reducing the sound pressure level (SPL) at $10 \mathrm{~dB}$ steps and finally at $5 \mathrm{~dB}$ steps up and down to identify the lowest level at which an $\mathrm{ABR}$ pattern was recognized.

Histopathology. Cross sections of inner ears were obtained in the following manner. Mice were anesthetized and perfused through the left ventricle of the heart with PBS, followed by Bouin's fixative. Midmodiolar cross sections were obtained by dissecting the inner ears out of the skull, immersing in Bouin's fixative for $24 \mathrm{~h}$, decalcifying in Cal-Ex solution for $6 \mathrm{~h}$, and embedding in paraffin. Sections were cut $(4 \mu \mathrm{m}$ thick), mounted on glass slides, and counterstained with hematoxylin and eosin. All slides were examined on an Olympus Optical (Tokyo,
Japan) BX40 light microscope, and digital images were captured with the Olympus Optical DP70 camera.

Scanning electron microscopy. Scanning electron microscopy (EM) was used to evaluate organ of Corti surface preparations. Inner ears were dissected from $14 \mathrm{jbg}$ mutants and 14 control mice [postnatal days 3 (P3), $\mathrm{P} 15, \mathrm{P} 25, \mathrm{P} 40$, and $\mathrm{P} 77$ ], fixed in $2.5 \%$ glutaraldehyde in $0.1 \mathrm{M}$ phosphate buffer, $\mathrm{pH} 7.2$ for $4 \mathrm{~h}$ at $4^{\circ} \mathrm{C}$, and then subjected to two 10 min washes in $0.1 \mathrm{~m}$ phosphate buffer. The outer shell of the cochlea and the stria vascularis were dissected away to expose the organ of Corti, and the sample was then postfixed with osmium tetroxide-thiocarbohydrazide, dehydrated, and critical point dried (Self et al., 1998). After mounting, samples were sputter coated to produce a $15 \mathrm{~nm}$ gold coating and examined at $20 \mathrm{kV}$ on a Hitachi (Tokyo, Japan) $3000 \mathrm{~N}$ scanning electron microscope. Images were archived using Quartz.PCI (version 5.1) software (Quartz, Vancouver, British Columbia, Canada).

Genetic mapping. To genetically map the mutation, individual DNA samples from linkage cross mice were typed for multiple microsatellite markers located throughout the mouse genome. Marker genotypes were then analyzed for cosegregation with the mutant phenotype. PCR primer pairs designed to amplify specific markers were purchased from Integrated DNA Technologies (Coralville, IA). PCRs comprised $50 \mathrm{ng}$ genomic DNA in a $10 \mu \mathrm{l}$ reaction volume containing $50 \mathrm{mM} \mathrm{KCl}, 10 \mathrm{~mm}$ Tris- $\mathrm{HCl}, \mathrm{pH} 9.0$ (at $25^{\circ} \mathrm{C}$ ), $0.01 \%$ Triton X-100, $2.25 \mathrm{~mm} \mathrm{MgCl}_{2}, 100 \mathrm{~nm}$ of each primer (forward and reverse), $100 \mu \mathrm{M}$ of each of four deoxyribonucleoside triphosphates, and $1.0 \mathrm{U}$ of TaqDNA polymerase (Amplitaq; catalog \#N808-0145; Applied Biosystems, Foster City, CA). PCR was performed in an MJ Research (Watertown, MA) PTC-200 Peltier Thermal Cycler. Amplification consisted of an initial denaturation at $97^{\circ} \mathrm{C}$ for $30 \mathrm{~s}$ followed by 40 cycles, each consisting of $94^{\circ} \mathrm{C}$ for $30 \mathrm{~s}$ (denaturation), 55 or $58^{\circ} \mathrm{C}$ for $30 \mathrm{~s}$ (annealing), and $72^{\circ} \mathrm{C}$ for $30 \mathrm{~s}$ for the first cycle and then increasing by $1 \mathrm{~s}$ for each succeeding cycle (extension). After the 40 cycles, the product was incubated for an additional $10 \mathrm{~min}$ at $72^{\circ} \mathrm{C}$ (final extension). PCR products were visualized on $4 \%$ NuSieve gels (Cambrex Bio Science, Rockland, ME).

DNA and RNA isolation, cDNA synthesis, and Northern blot analysis. Genomic DNA for mapping was prepared from mouse tail tips by using the Hot Shot procedure (Truett et al., 2000). Total RNA from whole brain, lung, skeletal muscle, liver, and kidney was isolated by digestion with Trizol reagent following the protocol of the manufacturer (Invitrogen, Carlsbad, CA). Total RNA from inner ears was obtained in the following manner. Whole inner ears (cochlea and vestibule) from each animal were pulverized in a $2.0 \mathrm{ml}$ Eppendorf (Westbury, NY) tube under liquid nitrogen, then extracted using Trizol reagent, and purified with the RNAqueous for PCR kit (Ambion, Austin, TX) according to the protocol of the manufacturer for steps 3-7. Mouse cDNA was synthesized with Superscript II reverse transcriptase according to the protocol of the manufacturer (Invitrogen). A Northern blot was prepared as described previously (Johnson et al., 1999) with $20 \mu \mathrm{g}$ samples of total RNA obtained from heart tissue of 4 -week-old $+/+,+/ j b g$, and $j b g / j b g$ mice and then hybridized with a Clic5 cDNA probe corresponding to nucleotides 216-1161 of GenBank accession number NM_172621.

DNA sequencing. PCR for comparative DNA analysis between $j b g$ mutant and control mice was performed according to the same conditions as described above for genetic mapping. PCR primers used to amplify specific regions of the Clic5 gene are given in supplemental Table 2 (available at www.jneurosci.org as supplemental material). Genomic and cDNA PCR products were purified with the QIAquick PCR Purification kit (Qiagen, Valencia, CA). DNA sequencing was performed using the same primers as for DNA amplification and then run on an Applied Biosystems 3700 DNA Sequencer with an optimized Big Dye Terminator Cycle Sequencing method.

SDS-PAGE and immunoblotting. Lung tissues from individual $+/+$, $+/ j b g$, and $j b g / j b g$ mice were homogenized in $4.5 \mu \mathrm{l}$ of double-strength reducing Laemmli's sample buffer per milligram of wet tissue weight, immediately boiled for $5 \mathrm{~min}$, and microcentrifuged for $5 \mathrm{~min}$ to remove insoluble debris. Proteins were resolved by $12 \%$ SDS-PAGE and visualized by Coomassie blue R-250 staining to verify equal protein loads. For immunoblots, proteins were transferred to polyvinylidene difluoride membranes and first probed with CLIC5 antibody preadsorbed against 
CLIC4 and peroxidase-labeled protein A as described previously (Berryman and Bretscher, 2000). Bands were visualized by ECL (Amersham Biosciences, Piscataway, NJ). Blots then were reprobed with a 1:2000 dilution of CLIC5 antiserum, which also recognizes CLIC4. Identification of CLIC4 and CLIC5 bands in tissue extracts was accomplished by loading total bacterial lysates containing $10 \mathrm{ng}$ of recombinant untagged CLIC4 or CLIC5 as positive control markers.

Immunohistochemical analysis of inner ears. Inner ears were dissected and fixed overnight in $4 \%$ paraformaldehyde at $4^{\circ} \mathrm{C}$. Inner ears from mice older than P7 were decalcified in 7\% EDTA/PBS for 1 week before embedding. Paraffin sections were cut $4 \mu \mathrm{m}$ thick and mounted on Superfrost plus slides (Fisher Scientific, Pittsburgh, PA). Free aldehydes were quenched by incubating slides in $150 \mathrm{~mm}$ glycine/TBS for $10 \mathrm{~min}$, followed by a quick rinse in $\mathrm{dH}_{2} \mathrm{O}$. Antigen retrieval was performed by boiling in antigen unmasking solution (Vector Laboratories, Burlingame, $\mathrm{CA}$ ) for $3 \mathrm{~min}$. Sections were rinsed in $\mathrm{dH}_{2} \mathrm{O}$ and blocked with $5 \%$ normal goat serum in TBS for 30-45 min at room temperature. CLIC5 antibody preabsorbed against CLIC4 (Berryman and Bretscher, 2000) diluted 1:14 in blocking solution or radixin-specific antibody (Pataky et al., 2004) diluted 1:800 were applied to mouse inner ear sections and incubated overnight at $4^{\circ} \mathrm{C}$. The following morning, sections were washed in TBS and incubated with anti-rabbit Alexa Fluor-488 (1:500) (Invitrogen). After washing in TBS, coverslips were mounted with Fluromount G (Electron Microscopy Sciences, Hatfield, PA). Fluorescent images were visualized using a Leitz (Wetzlar, Germany) DMRXE microscope with the appropriate fluorescent cubes and captured using a Leica (Nussloch, Germany) DC300FX digital camera with Leica Firecam (version 1.3) software. For immunoperoxidase detection of the radixin antibody, the Vectastain ABC kit (Vector Laboratories) was used according to the directions of the manufacturer with DAB chromogen as enzyme substrate. Slides were counterstained with hematoxylin.

Confocal microscopy immunocytochemistry. Inner ears from P3-P7 rats or embryonic day 19 (E19) to E20 chickens were fixed for 30 min with 3\% formaldehyde and were treated as above with antigen unmasking solution. Tissues were blocked in PBS containing 3\% normal donkey serum, $1 \%$ BSA, and $0.2 \%$ saponin and incubated overnight with CLIC5 antibody preabsorbed against CLIC4 (1:20) and AC- 15 anti- $\beta$-actin antibody (Sigma, St. Louis, MO). After washing with PBS (three times for 5 $\mathrm{min}$ ), tissues were incubated for $2 \mathrm{~h}$ with cyanine 5-labeled donkey antirabbit $(5 \mu \mathrm{g} / \mathrm{ml})$ and donkey anti-mouse antibodies $(5 \mu \mathrm{g} / \mathrm{ml})$. Images were obtained with a Bio-Rad (Hercules, CA) MRC 1024 confocal microscope, using a 60×, 1.4 numerical aperture objective.

Bundle purification and mass spectrometry protein identification. Hair bundles were isolated from E18 chicken utricle using an adaptation of the "twist-off" procedure (Gillespie and Hudspeth, 1991), to be described in detail later (J. B. Shin and P. G. Gillespie, unpublished data). Bundle proteins in agarose were reduced with DTT, carboxymethylated with iodoacetamide, and digested with trypsin; peptides were eluted with $1 \%$ formic acid, desalted, and subjected to GeLC (gel-enhanced liquid chromatography) (Rezaul et al., 2005) or MuDPIT (multidimensional protein identification technology) (Washburn et al., 2001) analyses. Tryptic peptides were separated on reverse-phase columns of $75 \mu \mathrm{m} \times 15 \mathrm{~cm}$, packed in-house with Astrosil ( $5 \mu \mathrm{m}$ particle size, 100 angstrom pore size, C18 reverse-phase chemistry; Stellar Phases, Langhorn, PA), using an Eksigent (Dublin, CA) NanoLC. Tandem mass spectrometry data were collected using a Qstar XL hybrid time-of-flight mass spectrometer (Applied Biosystems). Monoisotopic peak lists in MGF (Mascot generic format) were generated with Mascot Distiller software (Matrix Science, London, UK) and were searched against the En-

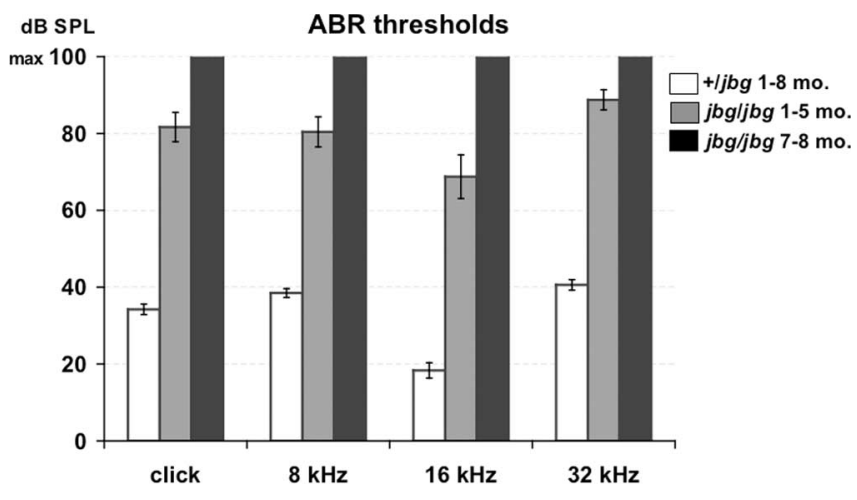

Figure 1. Assessment of hearing in $j b g$ mutants. Average ABR thresholds (with error bars indicating SE) for clicks and 8, 16, and $32 \mathrm{kHz}$ auditory stimuli are charted for three $\mathrm{jbg} / \mathrm{jbg}$ mutants at $7-8$ months of age, $12 \mathrm{jbg} / \mathrm{jbg}$ mutants at $1-5$ months of age, and $27+/ \mathrm{jbg}$ control mice at $1-8$ months of age. At $1-5$ months of age, $j b g / j b g$ mutants exhibit a profound hearing impairment, with $\mathrm{ABR}$ thresholds $>40 \mathrm{~dB}$ above those of $+/ j b g$ controls. All three $j b g / j b g$ mutants tested at 7-8 months of age were completely deaf; presentation of the maximum auditory stimulus (100 dB SPL) evoked no response in these mice.

sembl chicken database using the Global Proteome Machine website, which runs the X! Tandem algorithm (Craig et al., 2004). Mass spectrometry and peptide identification will be described in detail later (Shin and Gillespie, unpublished data).

\section{Results}

\section{The phenotype of $j b g$ mutant mice}

Jitterbug mutant mice $(j b g / j b g)$ are easily identified by their overt head bobbing and circling behavior and their inability to swim. These behavioral abnormalities generally indicate inner ear dysfunction, which often includes hearing impairment. To assess hearing in mutant and control mice, we measured their ABR thresholds. ABR thresholds of mutant mice at $1-5$ months of age were $40-50 \mathrm{~dB}$ above those of normal-hearing heterozygotes, and, by 7 months, jbg mutants showed no evoked responses to the highest auditory stimuli presented, indicating hearing loss progression to complete deafness (Fig. 1).
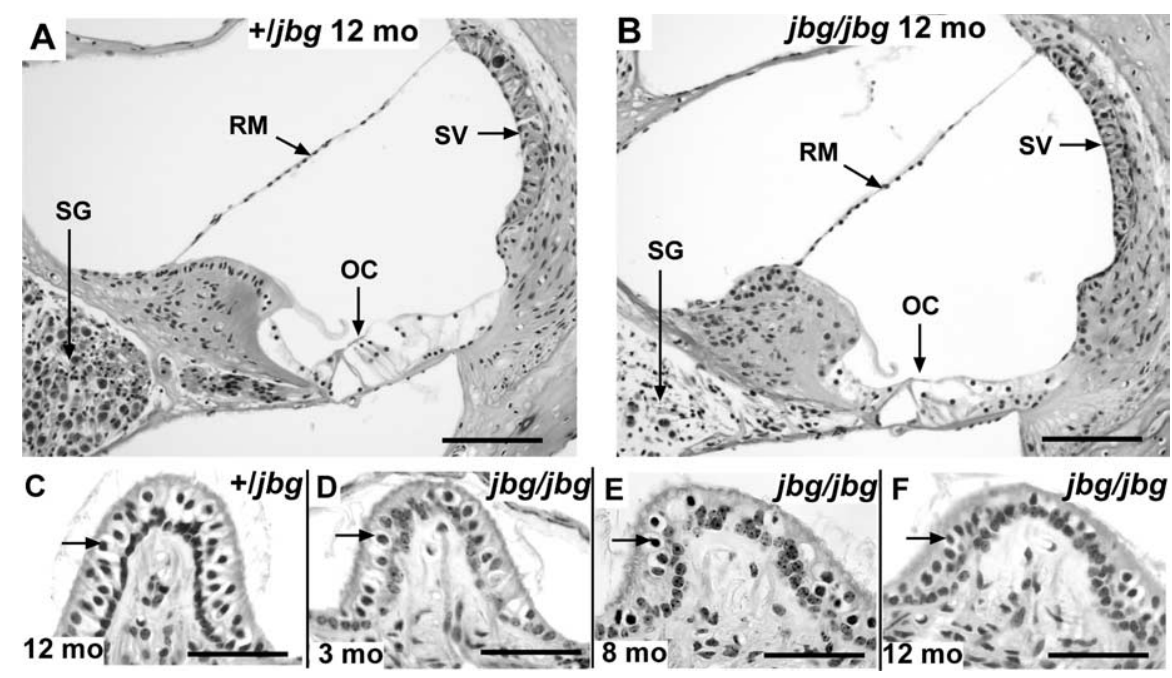

Figure 2. Inner ear histopathology of $j b g$ mutants. Cross sections through the midturn of a cochlea from a $+/ j b g$ control $(\boldsymbol{A})$ and a jbg/jbg mutant $(\boldsymbol{B})$ at 12 months of age. The organ of Corti has degenerated, and the density of spiral ganglion cells is greatly reduced in the mutant cochlea compared with the control. Other structures such as Reissner's membrane and stria vascularis remain intact in the mutant cochlea. OC, Organ of Corti; SG, spiral ganglion cells; RM, Reissner's membrane; SV, stria vascularis. Scale bars, $100 \mu \mathrm{m} . \mathbf{C}-\boldsymbol{F}$, Cross sections through the crista ampullaris of a $+/ j b g$ control at 12 months of age $(\boldsymbol{C})$ and $j b g / j b g$ mutants at $3(\boldsymbol{D}), 8(\boldsymbol{E})$, and $12(\boldsymbol{F})$ months of age. A progressive loss of hair cells is apparent in the mutant cristae. Arrows point to hair cells. Scale bars, $50 \mu \mathrm{m}$. 

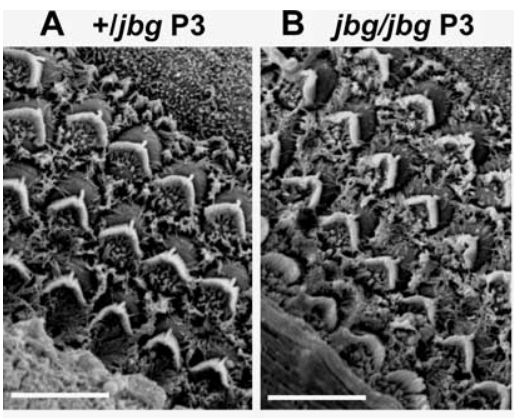

E +ljbg P77 basal turn

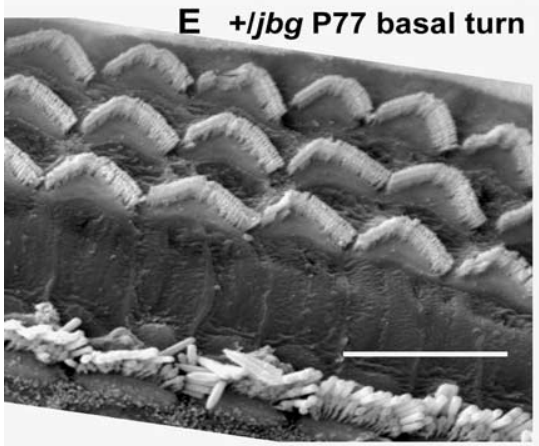

G jbg/jbg P25 mid turn
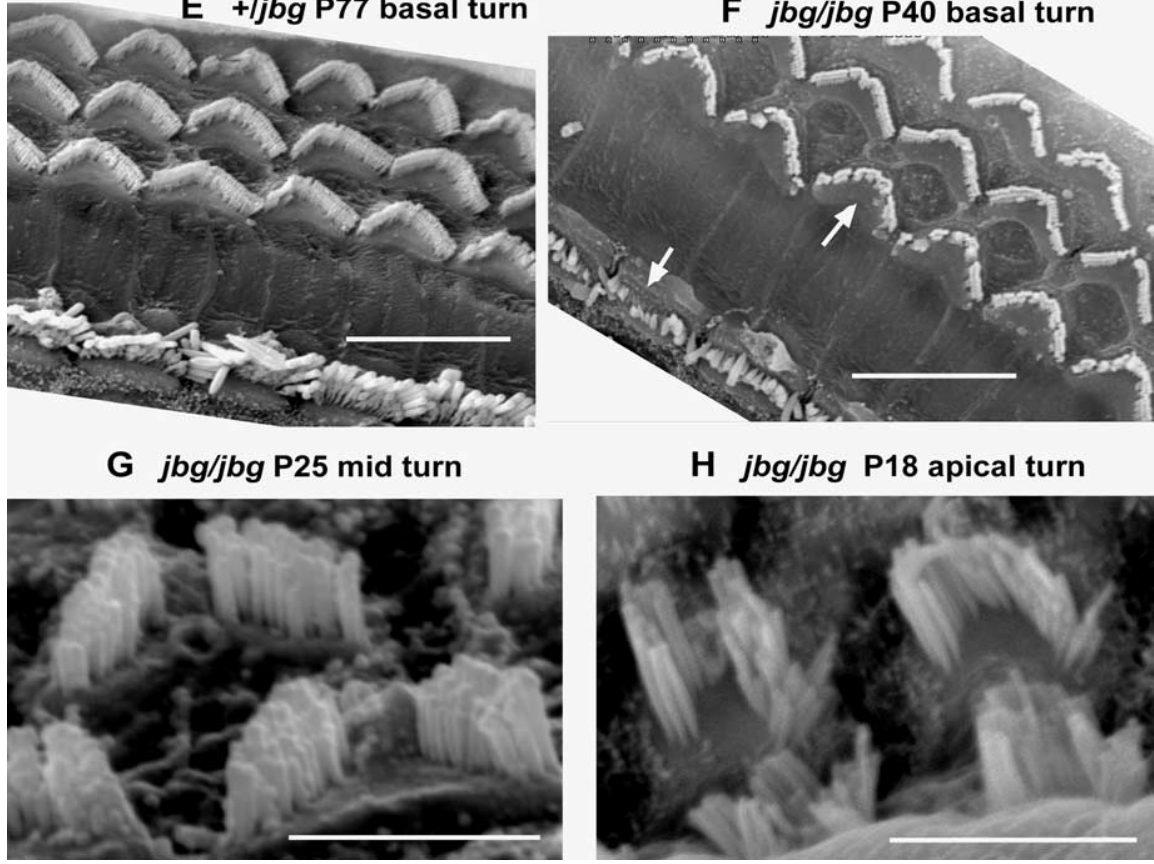

H jbg/jbg P18 apical turn

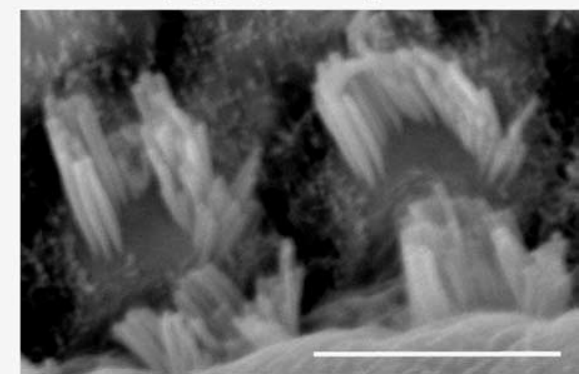

Figure 3. Scanning EM analysis of cochlear hair cells in jbg mutants. Stereocilia of cochlear hair cells of $+/ j b g$ control mice $(\boldsymbol{A}$, $\boldsymbol{C}, \boldsymbol{E})$ compared with those of $j b g / j b g$ mutants $(\boldsymbol{B}, \boldsymbol{D}, \boldsymbol{F}-\boldsymbol{H})$ at different ages. Stereocilia appear nearly normal in $j b g$ mutants at $P 3$ $(\boldsymbol{B})$, but by P15, stereocilia degeneration is apparent $(\boldsymbol{D})$, especially in the first row of outer hair cells. At P40, stereocilia degeneration in mutants $(\boldsymbol{F})$ appears slightly more extensive than at P15 and can be seen in both outer (upward pointing arrow) and inner (downward pointing arrow) hair cells; missing hair cells are not observed at this age. Scale bars: $\boldsymbol{A}-\boldsymbol{F}, 10 \mu \mathrm{m}$. Magnified views of outer hair cells $(\mathbf{G}, \boldsymbol{H})$ showing extensive stereocilia degeneration, especially at the bundle peak. Scale bars, $5 \mu \mathrm{m}$.

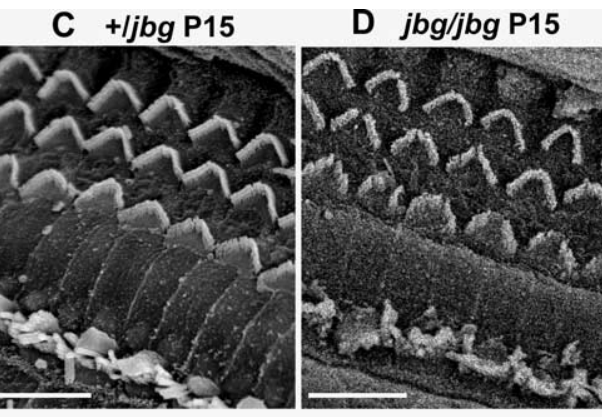

erate before those of inner hair cells. The hearing impairment exhibited by young mutant mice (which still retain some hearing) (Fig. 1) is likely related to the early loss of outer hair cell function. The later loss of inner hair cell function eventually culminates in deafness in mice by 7 months of age.

To assess the histological structures of organs other than the ear, a standard pathological analysis (http://www.jax.org/ mmr/Histology_Protocol.html) was performed on $j b g$ mutant and control mice at 11 months of age. No gross abnormalities were detected in any organs except for the lungs, which appeared to exhibit a progressive enlargement of alveolar air spaces in $j b g$ mutants compared with age-matched controls. This emphysema-like lung pathology is being further investigated.

\section{Clic5, a candidate gene for the jbg mutation}

The jbg mutation was genetically mapped using a previously described DNA pooling strategy (Taylor et al., 1994). DNA samples from 30 mutant $\mathrm{F} 2$ mice from an interspecific cross between $[\mathrm{C} 3 \mathrm{H} / \mathrm{HeJ}-j b g / \mathrm{J}(\mathrm{j} b g /$ $j b g) \times$ CAST/EiJ] F1 hybrids were pooled for a genome wide screen, and linkage was found with markers on mouse chromosome 17. To refine the map position of the mutation, genotypes of individual F2 progeny from this cross and genotypes of individual $\mathrm{N} 2$ progeny from a separate $[\mathrm{C} 3 \mathrm{H} / \mathrm{HeJ}-j b g / \mathrm{J}(j b g / j b g) \times \mathrm{C} 57 \mathrm{BL} / 6 \mathrm{~J}]$ $\mathrm{F} 1 \times \mathrm{C} 3 \mathrm{H} / \mathrm{HeJ}-j b g / \mathrm{J}(j b g / j b g)$ backcross were obtained for multiple chromosome 17 markers. Analysis of these data showed the location of the jbg mutation to be between D17Mit215 (43.1 Mb) and D17Mit235 (45.7 Mb) [megabase posi-

To investigate the anatomical basis of the hearing and balance dysfunction, we examined serial cross sections of inner ears by light microscopy and organ of Corti surface preparations by scanning EM. Cross sections through cochleae of $j b g$ mutants at 12 months of age showed a severe degeneration of the organ of Corti and a reduced density of spiral ganglion cells compared with controls (Fig. 2A,B). Other structures such as Reissner's membrane and stria vascularis were intact in the mutant cochlea. Vestibular hair cells also exhibited a progressive degeneration. In the crista ampullaris, vestibular hair cells were noticeably reduced in number in 3-month-old mutants and nearly absent in 12-monthold mutant mice (Fig. 2C-F). Scanning EM analysis of cochlear hair cells from P3 jbg mutants showed only a few minor stereocilia abnormalities compared with littermate controls, but the overall hair bundle orientation, patterning, and morphology appeared nearly normal (Fig. $3 A, B$ ). At later ages, abnormal and missing stereocilia were commonly observed in hair cells throughout the cochlear duct in $j b g$ mutants compared with agematched control mice and were particularly apparent in the first row of outer hair cells, often at the bundle peak (Fig. 3C-H). Stereocilia of outer hair cells in $j b g$ mutants appeared to degen- tions are from National Center for Biotechnology Information (NCBI) m36 assembly]. This large $2.6 \mathrm{Mb}$ region of mouse chromosome 17 contains at least 29 known genes. We considered one of these genes, Clic5, to be a particularly likely candidate for the jbg mutation because of the known association of CLIC5 protein with microvilli in polarized epithelial cells of human placenta (Berryman and Bretscher, 2000). Because inner ear hair cells are also polarized epithelial cells and their stereocilia are modified microvilli, we reasoned that a mutation of Clic5 might underlie the inner ear pathology observed in $j b g$ mutant mice.

The human CLIC5 gene extends over $144 \mathrm{~kb}$ of genomic DNA on chromosome 6 and comprises six exons with alternative first exons (Berryman and Bretscher, 2000; Shanks et al., 2002). CLIC5A and CLIC5B isoforms have distinct $\mathrm{N}$-terminal amino acids encoded by the alternative exons $1 \mathrm{~A}$ ( 21 amino acids) and 1B (180 amino acids), but share an identical C-terminal sequence (230 residues) containing the CLIC homology domain. The mouse Clic5 gene spans $\sim 145 \mathrm{~kb}$ on chromosome 17 and is very similar to the human gene in structure (Fig. $4 A$ ) (supplemental Table 1, available at www.jneurosci.org as supplemental material). The human and mouse CLIC5A proteins are identical in 
size and retain $96 \%$ sequence identity. The amino acids predicted from human and mouse exon $1 \mathrm{~B}$, however, differ in number and are not nearly as conserved in sequence as those of exon 1A. Human exon $1 B$ encodes 180 amino acids (Shanks et al., 2002) and mouse exon $1 \mathrm{~B}$ encodes 255 amino acids (supplemental Table $1 A$, available at www.jneurosci.org as supplemental material); their sequences are only $35 \%$ identical. Of all the known CLIC proteins, only CLIC5B (p64) and CLIC6 (parchorin) contain long $\mathrm{N}$-terminal stretches encoded by large first exons (Friedli et al., 2003). Among the mammalian species that have been examined, these N-terminal regions vary considerably in length, sequence, and repeat content. The mouse Clic5 exon 1B DNA sequence (supplemental Table $1 A$, available at www.jneurosci. org as supplemental material) encodes four nearly identical 28 amino acid repeats (SHSLSQDPERLPWEPQENGGATEEDVPS) that are not present in human and bovine sequences. Exon $1 \mathrm{~B}$ of bovine CLIC5 encodes four short amino acid repeats (QASDPEEP) that have been suggested to play a role in subcellular targeting (Redhead et al., 1997); however, these repeats are absent in the orthologous human and mouse sequences. The first exons of both human and rabbit CLIC6 encode a 10 amino acid motif that is repeated 14 times, but surprisingly, this repeat is not present in the mouse CLIC6 protein (Friedli et al., 2003). It is hard to reconcile this high degree of interspecific variability with any generalized functional constraints, although it is possible that these sequences have species-specific functional importance.

The sizes of the CLIC5 cDNA reference sequences for human (GenBank accession number NM_016929, 5703 bp) and mouse (GenBank accession number NM_172621, 5870 bp) approximate the $6.4 \mathrm{~kb}$ primary transcript size estimated from Northern blot analysis (Berryman and Bretscher, 2000; Shanks et al., 2002). To investigate additional 3.8 and $2.3 \mathrm{~kb}$ bands seen on Northern blots (Berryman and Bretscher, 2000; Shanks et al., 2002), we retrieved and analyzed multiple mRNA and EST sequences for mouse Clic5 from UniGene (Mm.37666). Alignment of these sequences with the public mouse genome sequence demonstrated that exon 6 of Clic5 ( $4955 \mathrm{bp}$ ) contains six consensus poly(A) sites (AATAAA), and transcripts predicted from alternative use of these sites appear to correspond with reported Northern blot transcript sizes and mRNA sequences (supplemental Table $1 B$, available at www.jneurosci.org as supplemental material). Multiple, alternative polyadenylation sites within the noncoding region of a single 3 '-terminal exon have been reported for many genes, and there is some evidence that small messages may be less stable but more readily translated than large transcripts (Edwalds-Gilbert et al., 1997). It is possible that tissue- or developmental stage-specific differences in transcription rates may influence the frequencies of the differently sized messages, and these differences may indirectly influence the level of protein expression. Northern blot results indicate that the most prevalent site for Clic5 polyadenylation is within a $54 \mathrm{bp}$ region that is highly conserved in rat, human, dog, cow, opossum, and chicken. This degree of evolutionary conservation may indicate a functional role in stabilizing this longest mRNA isoform.

\section{Identification of the $j b g$ mutation and Clic5 gene expression in mutant and control mice}

To evaluate the Clic5 gene in mutant and control mice, we designed PCR primers to amplify genomic DNA (NCBI m36 mouse assembly) and cDNA (Gen Bank accession number NM_172621) sequences. PCR primer sequences are listed in supplemental Table 2 (available at www.jneurosci.org as supplemental material). Amplified genomic DNAs from $j b g$ mutant mice and controls were scanned for potential size and sequence differences in each individual exon and flanking intron regions of the Clic5 gene. In DNA from mutant mice, primers for exons 1A, 1B, 2, 3, 4, and 6 produced amplicons of appropriate size equal to those of controls; however, the PCR product size for exon 5 was reduced in mutant DNA. Sequence analysis of the mutant amplicon identified a 97 bp deletion consisting of the $3^{\prime}$-most 87 bp of exon 5 and $10 \mathrm{bp}$ of the flanking intron sequence, including the exon/intron splice donor recognition sequence (Fig. $4 B$ ). Wild-type $(+/+)$, mutant $(j b g / j b g)$, and heterozygous $(+/ j b g)$ genotypes of mice could be distinguished easily by PCR with primers flanking exon 5 (Fig. 4C).

To analyze the difference between mutant and control Clic5 transcripts, a series of primers were designed to amplify overlapping cDNA fragments. Primers (WEX4F and WEX6R) that amplify the exon 4 to exon 6 region of Clic 5 cDNA detected a size difference between control (530 bp) and mutant (348 bp) reverse transcription (RT)-PCR products. Sequence analysis of these cDNA products from $j b g / j b g$ and $+/+$ mice revealed that the mutant transcript is precisely spliced from the $3^{\prime}$ end of exon 4 to the $5^{\prime}$ end of exon 6 (Fig. 5). The skipping of exon 5 creates a frame shift that alters two amino acids before introducing a premature stop codon. Gel analysis of the RT-PCR products showed that only mutant transcripts are produced in $j b g / j b g$ mice and that mutant transcripts are less abundant than wild-type transcripts in heterozygotes (Fig. 6A). Northern blot analysis of heart RNA could not detect a size difference between mutant and control mRNAs, which differ by only 182 nt; however, Clic5 transcript levels, relative to $A c t b$ (actin $\beta$ ) controls, appeared much reduced in $j b g$ mutant mice. From a quantitative analysis of band intensities, we estimated that Clic5 transcripts of $+/ j b g$ and $j b g / j b g$ mice are $\sim 70$ and $20 \%$, respectively, as abundant as those of $+/+$ mice (Fig. 6B). 
A

\section{$+1+$ cDNA sequence}

ACC GCG GGC ATC GAC ATC TTC TCC AAG TTC TCA GCC TAC ATC AAA. $\begin{array}{lllllllllllllll}T & A & G & I & D & I & F & S & K & F & S & A & Y & I & K\end{array}$

$\begin{array}{ccccccccccccccc}\text { AAC } & \text { ACC } & \text { AAA } & \text { CAA } & \text { CAG } & \text { AAC } & \text { AAT } & \text { GCT } & \text { GCC } & \text { CTT } & \text { GAG } & \text { AGA } & \text { GGC } & \text { TTG } & \text { ACA } \\ \text { N } & \text { T } & K & Q & Q & N & N & \text { A } & \text { A } & \text { L } & \text { E } & \text { R } & \text { G } & \text { L } & \text { T }\end{array}$

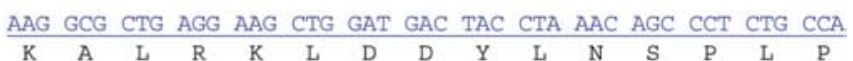

GAG GAG ATT GAC ACC AAC ACC CAC GGG GAC GAG AAG GGG TCC CAG

\begin{tabular}{lllllllllllllll}
\hline E & E & I & D & T & N & T & H & G & D & E & K & G & S & Q
\end{tabular}

CGC AAG TTC CTG GAT GGG GAT GAG CTG ACC CTG GCC GAC TGC AAT

CTG CTG CCC AAG CTG CAT GTG GTC AAG ATT GTG GCT AAG AAG TAC

CGA AAC TAT GAC ATC CCA GCT GAG ATG

$\begin{array}{lllllllll}R & N & Y & D & I & P & A & E & M\end{array}$

\section{$j b g / j b g$ cDNA sequence}

ACC GCG GGC ATC GAC ATC TTC TCC AAG TTC TCA GCC TAC ATC AAA $\begin{array}{lllllllllllllll}T & \mathrm{~A} & \mathrm{G} & \mathrm{I} & \mathrm{D} & \mathrm{I} & \mathrm{F} & \mathrm{S} & \mathrm{K} & \mathrm{F} & \mathrm{S} & \mathrm{A} & \mathrm{Y} & \mathrm{I} & \mathrm{K}\end{array}$

AAC ACC AAA CAA CAG AAC AAT GCT GAT TGT GGC TAA

$\begin{array}{llllllllllll}N & T & K & Q & Q & N & N & A & D & C & G & S T O P\end{array}$

\section{B}

$+/+$

A A C A G A A C A A T G C C I G G C C C C I T T G A G A G A homprownmm

$j b g / j b g$

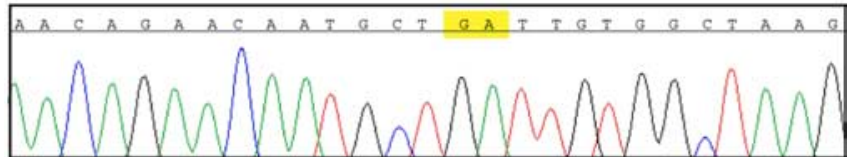

Figure 5. Comparison of mutant and control Clic 5 CDNA sequences. $A$, Partial CDNA sequence and amino acid translation of Clic5 from wild-type $(+/+)$ and mutant $(\mathrm{jbg} / \mathrm{jbg}$ ) mice. Nucleotides corresponding to exon 5 are shown in blue for the $+/+$ cDNA sequence. Exon 5 is entirely skipped in Clic5 transcripts from $\mathrm{jbg} / \mathrm{j}$ gg mutants. The nucleotides highlighted in yellow indicate the normal exon 4-5 splice junction (GC) in $+/+$ CDNA and the abnormal exon 4-6 splice junction (GA) in the jbg mutant transcript, which causes a translational frame shift and introduces a premature stop codon (red) in exon 6. B, Comparison of CDNA sequence chromatograms of $+/+$ (top) and $j b g / j b g$ (bottom) mice, illustrating the precise deletion of exon 5 in the jbg mutant transcript.

We next used RT-PCR analysis to evaluate Clic5 gene expression in multiple tissues from wild-type mice (Fig. 6C). Primers corresponding to the alternative exons $1 \mathrm{~A}$ and $1 \mathrm{~B}$ were designed to distinguish between Clic5A and Clic5B mRNA isoforms. Clic5A was detected in all tissues examined (lung, brain, heart, kidney, and inner ear), whereas Clic5B was detected only in kidney and, to a lesser extent, brain. In kidney tissue, the ratio of Clic5B to Clic5A was greater in mice at age P15 than at age P0. A basic local alignment search tool (BLAST) search of mouse expressed sequence tags (ESTs) with an exon 1A-specific sequence retrieved 12 hits, derived from a wide variety of tissues, including placenta, adrenal gland, thymus, spleen, kidney, lung, bone, embryo, and neonate head. In contrast, a BLAST search with an exon 1B-specific sequence retrieved only three matches, one derived
A

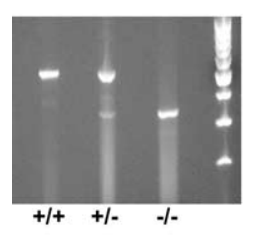

B

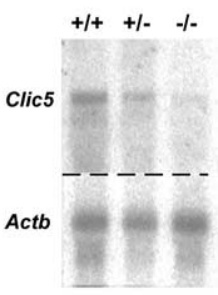

C
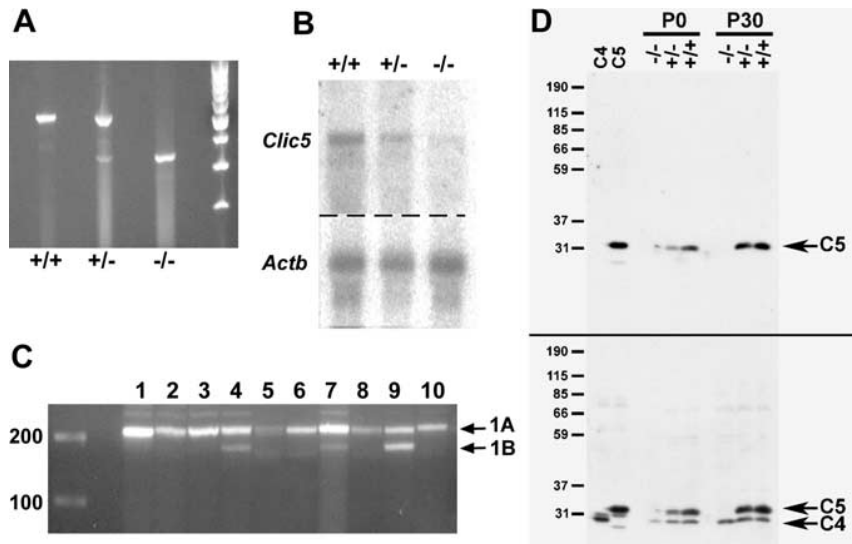

Figure 6. CLIC5 gene and protein expression in wild-type mice $(+/+),+/ j b g$ heterozygotes $(+/-)$, and $j b g / j b g$ mutants $(-/-)$. A, RT-PCR analysis of Clic 5 expression in mutant and control mice. Primers corresponding to sequences within exons 4 and 6 of $C l i c 5$ were used to amplify cDNA produced from heart tissue of $-/-,+/-$, and $+/+$ mice. A 530 bp product was obtained from $+/+$ cDNA and a 348 bp product from $-/-$ cDNA. Both products were obtained from $\pm /-C D N A$, although the 348 bp mutant product was less abundant than the 530 bp wild-type product. $\boldsymbol{B}$, Northern blot analysis of Clic 5 expression in mutant and control mice. Total RNA (20 $\mu \mathrm{g} /$ lane) extracted from heart tissue of 4 -week-old $+/+($ lane 1$),+1-$ (lane 2), and - /- (lane 3) mice was hybridized with a cDNA probe for Clic5 and then rehybridized with an Actb cDNA probe. By quantifying band intensities and adjusting for Actb control variation, the $6.4 \mathrm{~kb}$ Clic5 transcripts of $+/-$ and $-/-$ mice were estimated to be $\sim 70$ and $20 \%$ those of $+1+$ mice, respectively. C, RT-PCR analysis of Clic5 expression in multiple tissues of $+/+$ mice. Primers WEX1AF and WEX2R amplify a 214 bp cDNA product that is specific for exon $1 A$, and primers WEX1BF and WEX2R amplify a 183 bp product specific for exon 1B. Multiplex reactions containing all three primers were used to evaluate the relative abundance of Clic5A and Clic5B transcripts in lung (lanes 1,6), brain (lanes 2,7), heart (lanes 3,8), kidney (lanes 4, 9), and inner ear (lanes 5, 10) tissues of mice at ages P2 (lanes 1-5) and P15 (lanes $6-10)$. D, Western blot analysis of CLIC4 and CLIC5 protein expression in lungs of $j b g$ mutant and control mice. Total SDS extracts of lung tissue from $-1-,+1-$, and $+1+$ mice at ages $\mathrm{PO}$ and P30 were first probed with CLIC5 antibody that was preabsorbed against CLIC4 (top). The same blot then was reprobed with whole antiserum against CLIC5 (bottom), which also crossreacts with the slightly faster migrating CLIC4. Approximately $10 \mathrm{ng}$ of freshly prepared recombinant, untagged, human CLIC4 and CLIC5 were loaded as positive control markers. Positions of molecular weight markers (kilodaltons) are shown on the left. The blots clearly show the absence of CLIC5 in mutant $j b g / j b g$ mice $(-/-)$. In contrast, the level of CLIC4 is similar in mice of all three genotypes. C4, CLIC4; C5, CLIC5.

from whole brain (CF538435) and two from kidney (AI036756 and BX525157). Because both CLIC5A and CLIC5B protein isoforms are absent in $j b g$ mutant mice, their differential effects on phenotype cannot be directly compared; however, on the basis of tissue-specific differences in expression, a deficiency of the CLIC5A isoform most likely underlies the inner ear pathology observed in $j b g$ mutants.

\section{CLIC5 protein expression and inner ear localization}

To evaluate CLIC5 antibody specificity and examine CLIC5 protein expression in $j b g$ mutant and control mice, we first performed Western blot analysis using total SDS extracts of lung tissues from $\mathrm{P} 0$ and $\mathrm{P} 30+/+,+/ j b g$, and $j b g / j b g$ mice (Fig. $6 D$ ). The blot was first probed with a CLIC5 antibody that was preabsorbed against CLIC4. The blot was then reprobed with whole antiserum against CLIC5, which also cross-reacts with the slightly faster migrating CLIC4. CLIC5 was abundant in $+/+$ and $+/ j b g$ mice but was not detectable in $j b g / j b g$ mutants. The CLIC4 crossreactive protein, which served as an internal control, was observed in mutant and control mice at both ages. These results confirmed the absence of CLIC5 protein (but not CLIC4) in $j b g$ / 

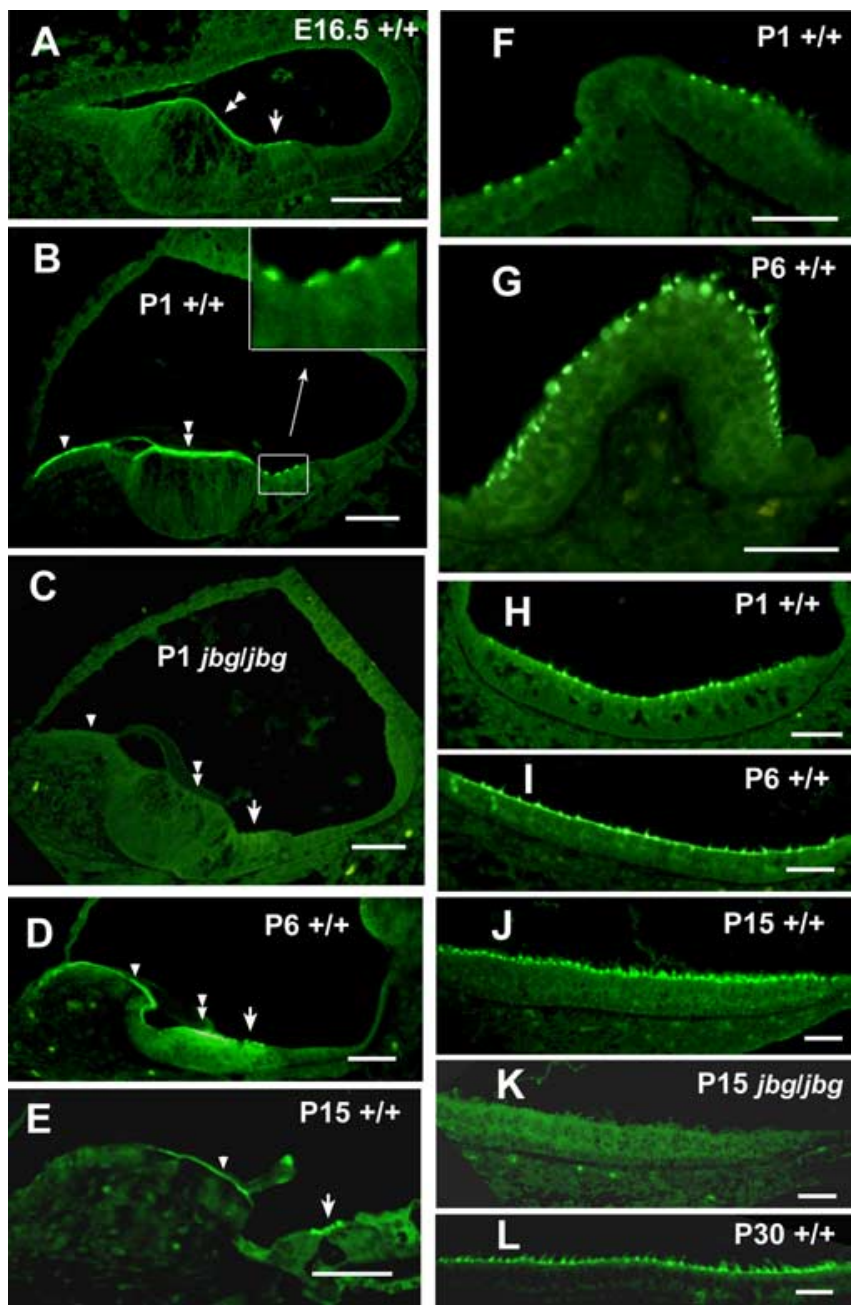

Figure 7. Immunolocalization of CLIC5 in the inner ear. Within the cochleae of wild type $(+/+)$ mice at ages E16.5 (A), P1 (B), and P6 (D), CLIC5 localized to microvilli-covered apical surfaces of interdental cells (single arrowheads) and columnar cells of Kolliker's organ (double arrowheads) and to stereocilia of inner and outer hair cells (arrows; inset in $\boldsymbol{B}$ ). At P15 (E) and P30 (data not shown), CLIC5 immunofluorescence was most intense in hair cell stereocilia. CLIC5 also was detected in stereocilia of vestibular hair cells, in the cristae of the semicircular canals $(\boldsymbol{F}$, $\boldsymbol{G})$ and in the maculae of the saccule $(\boldsymbol{I}, \boldsymbol{L})$ and utricle $(\boldsymbol{H}, \boldsymbol{J})$ of wild-type mice at all ages tested (P1-P30). CLIC5 was not detected in cochleae ( $\boldsymbol{C}$, maculae $(\boldsymbol{K})$, or cristae (data not shown) of jbg/jbg mutant mice at any age. Scale bars, $50 \mu \mathrm{m}$.

jbg mutant mice and verified the specificity of the CLIC5 antibody when preadsorbed against CLIC4.

To determine the localization of CLIC5 within the inner ear, we used the CLIC5 antibody that was preabsorbed against CLIC4. We examined inner ears from E16.5, P1, P6, P15, and P30 mice and detected CLIC5-specific fluorescence in cross sections from control mice but not in sections from $j b g / j b g$ mutants (Fig. 7). In cochlea of wild-type mice at E16.5, P1, and P6, CLIC5 fluorescence was detected along the microvilli-rich apical surfaces of interdental cells and columnar cells of Kolliker's organ, and in stereocilia of inner and outer hair cells (Fig. 7A-D). By P15, CLIC5 immunofluorescence in the cochlea appeared most intense in hair cell stereocilia (Fig. 7E). CLIC5 also was detected in stereocilia of vestibular hair cells of the cristae ampullares and maculae of the utricle and saccule at all ages examined (Fig. $7 F-$ $L$ ). CLIC5 could not be detected in the cochlea (Fig. $7 C$ ) or any of the vestibular organs (Fig. $7 \mathrm{~K}$ ) in inner ears from $j b g / j b g$ mutant mice at any age.
To refine the location of CLIC5 in the hair bundle, we examined whole mounts of rat cochlear and vestibular organs by confocal microscopy using the same CLIC5 antibody preadsorbed against CLIC4. CLIC5 immunoreactivity was prominent in stereocilia of early postnatal and adult inner and outer hair cells (Fig. $8 \mathrm{~A}-J$ ). In vestibular hair bundles, CLIC5 was clearly concentrated in the bottom of half of hair bundles examined in early postnatal rats (Figs. $8 \mathrm{~K}-\mathrm{M}, 9 \mathrm{~A}$ ); this distribution was nearly identical to that of radixin (Fig. 9B), as reported previously (Pataky et al., 2004). Although nearly all CLIC5 immunoreactivity was present in hair bundles, we detected a small amount of CLIC5 signal in cell bodies of hair cells, surrounding the cuticular plate. No CLIC5 immunoreactivity was observed in supporting cells.

Because of their similar distributions in the hair bundle, we tested for a possible CLIC5-radixin interaction by examining radixin immunoreactivity in hair bundles of $j b g / j b g$ mutants, which completely lack CLIC5, compared with littermate control mice. We examined multiple cross sections of inner ears from one mutant and one control at three different ages (P1, P15, and P30) and used both peroxidase and fluorescence procedures for antibody detection. We consistently found diminished radixin immunostaining in hair bundles of CLIC5-deficient mice $(j b g / j b g)$ compared with those of $+/+$ controls, which was most apparent in vestibular hair cells of the maculae and cristae ampullaris (Fig. 10). These results suggest that CLIC5 may help to localize or stabilize radixin on the hair bundle.

\section{CLIC5 protein expression in purified hair bundles}

We confirmed the localization of CLIC5 to stereocilia using protein biochemistry with purified hair bundles of the chick utricle. We adapted the twist-off bundle isolation method (Gillespie and Hudspeth, 1991) to bundles of E18 chicken utricles (Shin and Gillespie, unpublished data). Bundle proteins were identified from this preparation using tandem mass spectrometry (Domon and Aebersold, 2006). CLIC5 was readily detected, identified in each of six independent mass spectrometry runs with a $\log (e)$ value, the statistical confidence score (expectation value) calculated from the X!Tandem algorithm (Craig and Beavis, 2004), as small as -140 (Fig. 11 A). We identified one peptide only found in CLIC5A (Fig. 11B) and none that were exclusive for CLIC5B, confirming that CLIC5A is the principal hair bundle splice variant. Sequence coverage for CLIC5 was as high as 57\% (Fig. 11C). CLIC4 was never identified in hair bundles. Using spectral-count measurements as a semiquantitative measure of protein abundance (Liu et al., 2004), we estimated that CLIC5 accounted for $\sim 1 \%$ of the total bundle protein, similar to that of radixin (Shin and Gillespie, unpublished data). Consistent with the mass spectrometry results, protein immunoblotting of purified chicken hair bundles detected a band of $\sim 40 \mathrm{kDa}$ (Fig. $11 D$ ), corresponding to the size of CLIC5A. In chicken utricle hair bundles, like in rat vestibular bundles, CLIC5 was also located in the lower half of the bundle (Fig. 11E).

\section{Discussion}

We present several lines of evidence demonstrating that a mutation in the Clic5 gene underlies inner ear dysfunction in jbg mutant mice. First, Clic5 is included within the candidate gene region of the $j b g$ mouse mutation. Second, $j b g$ mutant phenotypes agree with Clic5 mutation genotypes in all mice examined $(n=$ 135). Third, the absence of CLIC5-positive bands in Western blots of lung tissue from jbg mutants and the lack of specific CLIC5 immunofluorescence in inner ear sections of $j b g$ mutants 

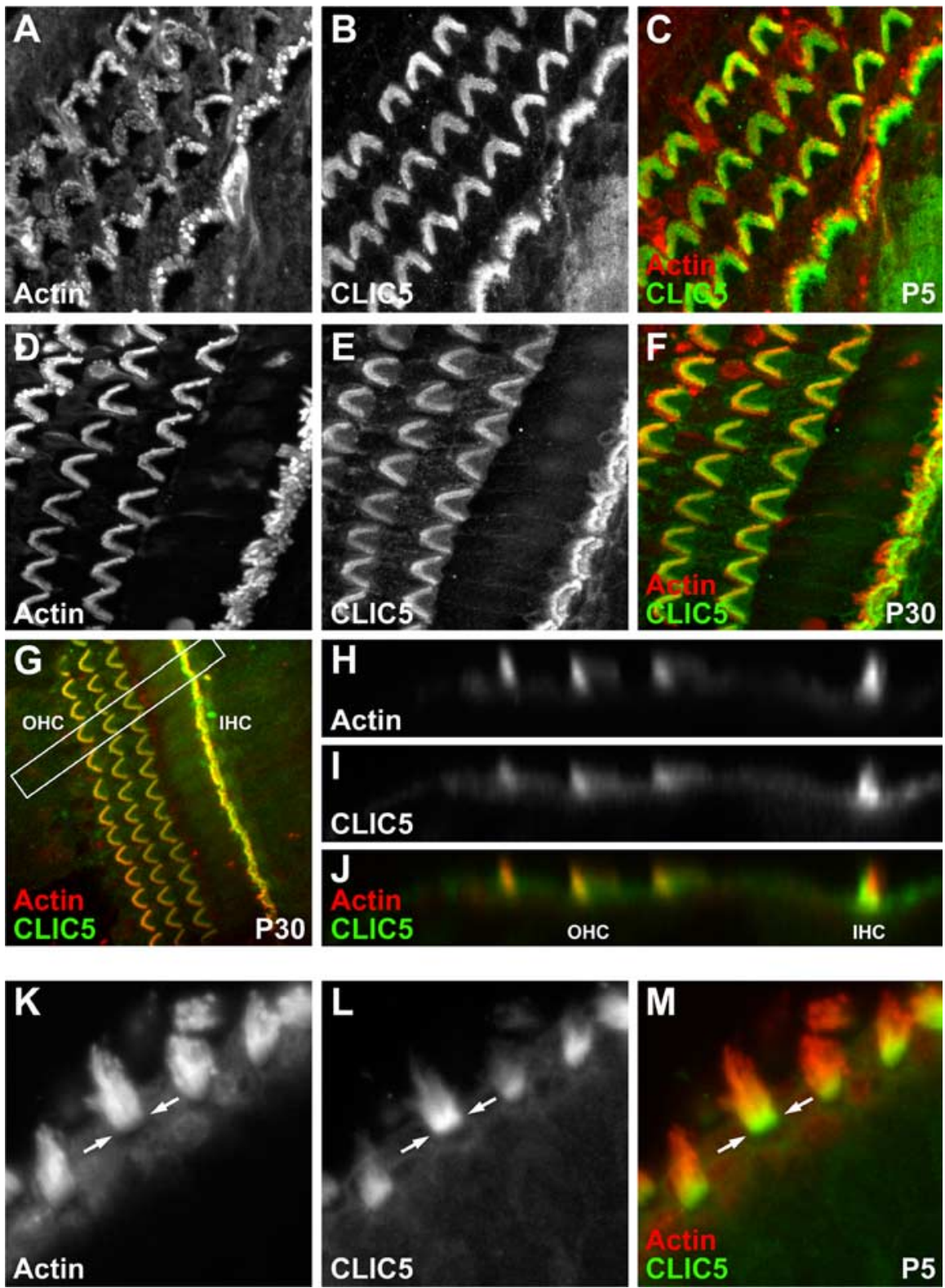

Figure 8. Confocal microscopic localization of CLIC5 in rat cochlear and vestibular hair bundles. $A-C$, Rat P5 organ of Corti labeled with anti-CLIC5 (green in C) and anti- $\beta$-actin (red in C). D-J, Rat P30 organ of Corti labeled with anti-CLIC5 and anti- $\beta$ actin. An $x-z$ plot was generated from the boxed region in $\mathbf{G}$ to give cross sections in $\boldsymbol{H}-J$. Note that $C L I C 5$ is nearly exclusively located in bundles of inner and outer hair cells. $\boldsymbol{K}-\boldsymbol{M}$, Rat utricle labeled with anti-CLIC5 (green in $\boldsymbol{M}$ ) and anti- $\beta$-actin (red in $\boldsymbol{M}$ ); arrows indicate base of hair bundle at the apical surface. Panel horizontal widths: $A-F, 48 \mu \mathrm{m} ; \mathbf{G}-J, 96 \mu \mathrm{m} ; \boldsymbol{K}-\boldsymbol{M}, 32 \mu \mathrm{m}$.

the subcellular localization of the CLIC5 protein in the basal region of the hair bundle. During mouse cochlear development from E16.5 through P6, CLIC5 is found in close association with microvilli on the apical surfaces of interdental cells and columnar epithelial cells of Kolliker's organ and with stereocilia of inner and outer hair cells. The apical surfaces of epithelial cells of Kolliker's organ are covered in a dense field of microvilli, which are lost during transformation of these columnar cells to adult cuboidal form. This loss of microvilli coincides with the decrease of CLIC5 expression observed in these cells during this developmental period. By P30, expression within the inner ear is highest in hair cell stereocilia. The spatial pattern of CLIC5 expression in the inner ear closely follows that described for filamentous actin, which is specifically expressed along the apical surfaces of cells of Kolliker's organ and of cochlear and vestibular hair cells (Anniko et al., 1987; Romand et al., 1993), and the similarity of expression patterns may reflect the previously reported association of CLIC5 with actin-based cytoskeletal structures of other tissues (Berryman and Bretscher, 2000).

Mouse mutations have aided in the identification and characterization of several other genes whose products localize to hair cell stereocilia, including Myo7a (myosin VIIa) (Gibson et al., 1995), Myo6 (Avraham et al., 1995), Myo15 (Probst et al., 1998), Espn (espin) (Zheng et al., 2000), Cdh23 (cadherin 23) (Di Palma et al., 2001), Pcdh15 (protocadherin 15) (Alagramam et al., 2001), Ush1g (Usher syndrome 1g) (Kikkawa et al., 2003), Ush1c (Johnson et al., 2003), Whrn (whirlin) (Mburu et al., 2003), $R d x$ (radixin) (Kitajiri et al., 2004), and Tmhs (tetraspan transmembrane protein of hair cell stereocilia) (Longo-Guess et al., 2005). The $R d x$ mouse model is of particular interest in comparison with the $j b g$ mutation of Clic5. Radixin is a member of the ezrin-radixinmoesin (ERM) family of proteins. ERM

indicate an absence of the Clic5 gene product. Fourth, the spontaneous and coisogenic nature of the $j b g$ mutation makes it highly unlikely that a different DNA alteration is responsible for the mutant phenotype. The $j b g$ mutation appears to be functionally null with a complete lack of protein expression. The 96 bp deletion in the Clic5 gene of $j b g$ mice causes precise skipping of exon 5 , thus creating a frame shift and premature stop codon in both Clic5A and Clic5B transcripts, effectively generating null mutations of both transcripts. The human CLIC5 gene has been mapped to the 6p21.2-p12.1 chromosome region and may be considered a candidate gene for human deafness disorders that map to this region; however, none have been reported to date.

Our results provide the first evidence for expression of CLIC5 (specifically the CLIC5A isoform) in the inner ear and establish proteins are concentrated in surface projections of epithelial cells, in which they are thought to link actin microfilaments to the plasma membrane (Bretscher et al., 1997). Ezrin was previously shown to be tightly associated with CLIC5 in placental microvilli (Berryman and Bretscher, 2000), and both ezrin and radixin were shown to be present in hair cell stereocilia (Kitajiri et al., 2004; Pataky et al., 2004). Although inner ear abnormalities have not been reported in ezrin-deficient mice (Saotome et al., 2004), radixin-deficient mice $\left(R d x^{-/-}\right)$exhibit a profound hearing loss (Kitajiri et al., 2004). Cochlear stereocilia appear to develop normally but begin to degenerate with the onset of hearing at approximately P14; stereocilia of vestibular hair cells do not degenerate. In adult $R d x^{-/-}$mutant mice, ezrin appears to compensate for radixin deficiency in the maintenance of vestibular but not co- 


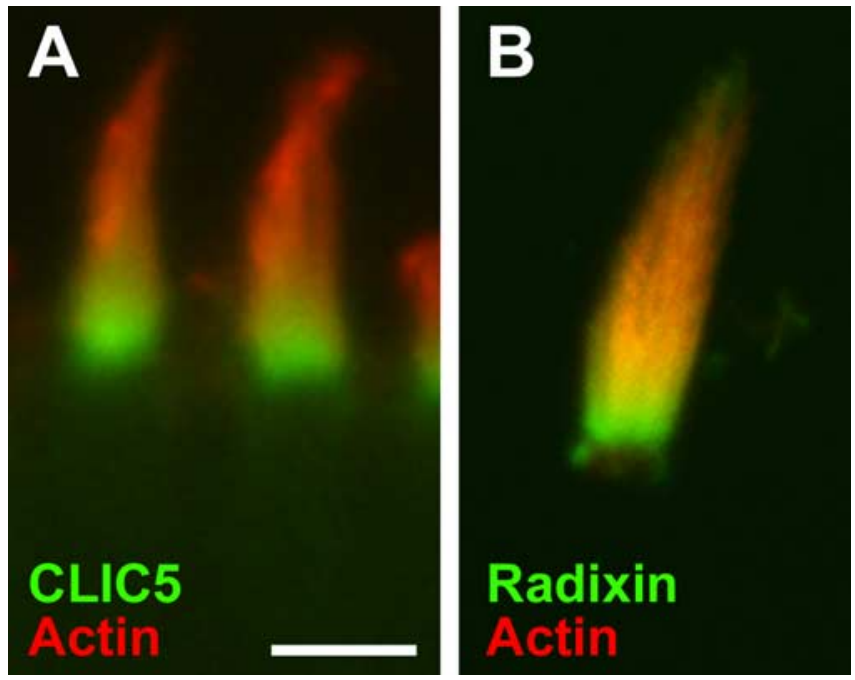

Figure 9. Similar location of $\mathrm{CLIC} 5$ and radixin in rat utricle hair bundles. $A$, Rat utricular hair bundles labeled with anti-CLIC5 (green) and anti- $\beta$-actin (red). $\boldsymbol{B}$, Rat utricle hair bundle labeled with anti-radixin (green) and phalloidin (red, to label actin). Radixin is also located at the base of the hair bundle. Scale bar: $A, B, 5 \mu \mathrm{m}$.

chlear stereocilia, consistent with its differential expression (Kitajiri et al., 2004).

Although the cochlear pathology of CLIC5-deficient jbg mice is similar to that of $R d x$ mutant mice, $j b g$ mutants exhibit obvious signs of vestibular dysfunction in addition to hearing loss. The degeneration of both cochlear and vestibular hair cells in CLIC5deficient $j b g$ mice may be caused by the loss of both ezrin- and radixin-mediated functions, if binding with CLIC5 is needed for their activity. CLIC5 binding to ERM proteins may help to localize or stabilize them or maintain them in an active conformation, thereby enhancing their ability to crosslink actin filaments with the plasma membrane.
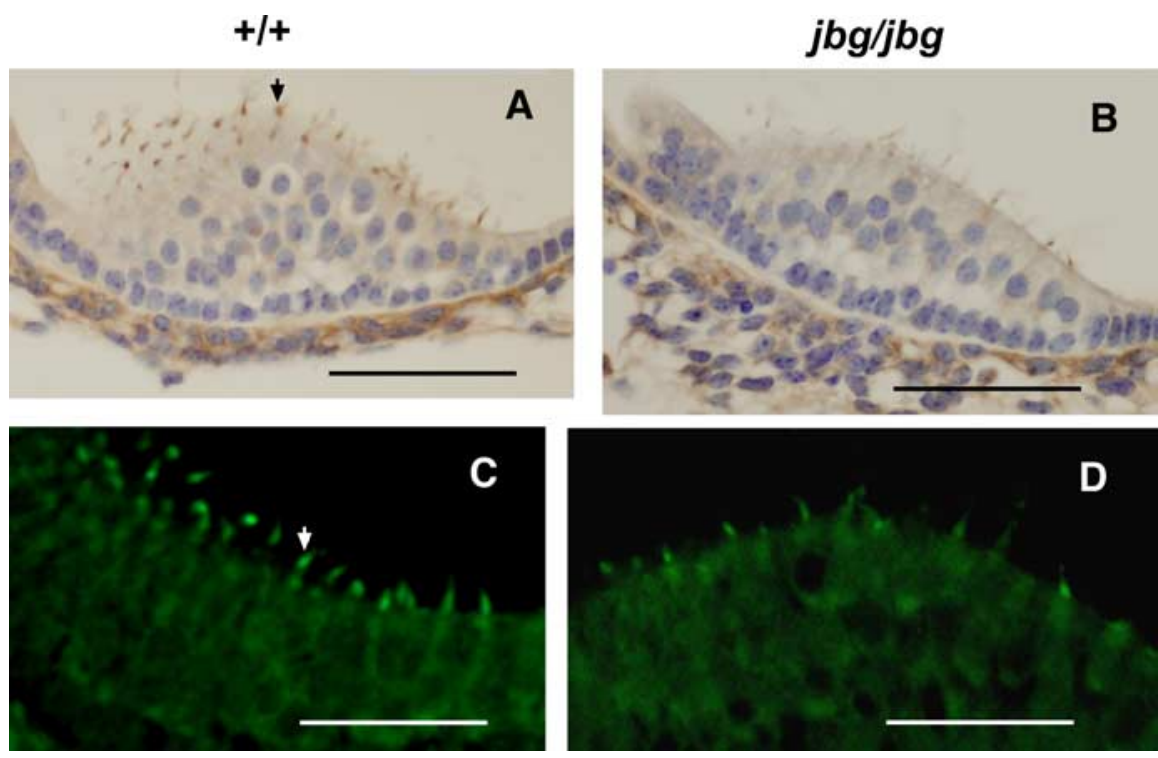

Figure 10. Immunolocalization of radixin in hair bundles of $j b g$ mutant and control mice. Paraffin-embedded inner ear cross sections from P1 mice were incubated with radixin primary antibody. $\boldsymbol{A}, \boldsymbol{B}, \mathrm{DAB}$ immunoperoxidase detection of radixin in hair bundles of the crista ampullaris, counterstained with hematoxylin. $\boldsymbol{C}, \boldsymbol{D}$, Fluorescent detection of radixin in hair bundles of the crista ampullaris. Radixin immunostaining of hair bundles was reduced in CLIC5-deficient mice ( $j b g / j b g ; \boldsymbol{B}, \boldsymbol{D})$ compared with wild-type mice ( $+/+; \boldsymbol{A}, \boldsymbol{C}$ (hair bundles indicated by arrows).
Results presented in this paper indicate that CLIC5 may indeed associate with radixin in inner ear hair bundles. CLIC5 and radixin are both distributed along the bottom half of stereocilia (Figs. 8, 9), radixin immunostaining is reduced in hair bundles of CLIC5-deficient mice (Fig. 10), and CLIC5 and radixin are present in approximately equimolar amounts in purified hair bundles of the chick utricle. Consistent with our evidence for a CLIC5-radixin association, previous results from yeast twohybrid analysis of rat brain cDNA have shown an interaction of radixin with the carboxy end of CLIC6, which is highly conserved in all CLIC proteins (Griffon et al., 2003). Like CLIC5 and radixin, protocadherin 15 and myosin VIIa also localize toward the base of developing stereocilia (Senften et al., 2006), and myosin VIIa has a FERM (4.1 and ERM protein) binding domain. It is possible that all of these proteins are components of the same membrane-cytoskeletal complex; however, myosin VIIa expression appears unaltered in hair cells of $j b g$ mutant mice (data not shown).

That CLIC5 associates with membrane-cytoskeletal complexes does not clarify whether it is a peripheral membrane protein required for maintenance of the cytoskeleton or an integral membrane protein that functions as a cytoskeletal-linked chloride ion channel. In other mutant mouse models, disturbed chloride ion transport in the inner ear has been shown to affect endolymph volume. Mice lacking a functional Slc12a2 (a sodiumpotassium-chloride transporter) gene exhibit reduced endolymph secretion and a collapsed Reissner's membrane in the cochlea (Dixon et al., 1999), and mice with null mutations of Slc26a4 (the Pendred syndrome chloride-iodide transporter) display endolymphatic dilatation and an enlarged endolymphatic sac of the inner ear (Everett et al., 2001). Neither of these phenotypes, which indicate endolymph ion imbalance, were observed in $j b g$ mutant mice, suggesting that chloride ion gating is not a primary function of CLIC5 in the inner ear. This interpretation is consistent with the failure to detect bulk anion efflux in epithelial cells stably transfected with CLIC5, in which CLIC5 is highly enriched in apical microvilli and colocalizes precisely with ezrin (Berryman et al., 2004). In support of the view that CLIC5 associates with the cortical actin cytoskeleton, in vitro binding experiments using immobilized CLIC5 show that it can promote de novo assembly of cytoskeletal complexes containing ezrin and actin and also suggest that CLIC5 may interact directly with ezrin (Berryman et al., 2004).

In CLIC5-deficient mice, stereocilia appear to develop normally and subsequently degenerate with age, followed by hair cell degeneration and consequent inner ear dysfunction. Given that CLIC5 appears to associate with a radixin-actin cytoskeletal complex in inner ear stereocilia, it may help form or stabilize connections between the plasma membrane and the cortical actin cytoskeleton and function in cytoskeletal assembly or maintenance, membrane-protein localization, or signal transduction. The jbg mutant mouse provides a valuable mammalian model system to further investigate CLIC5 function in vivo and to analyze the pathophysiological mechanisms that underlie hearing impair- 
A

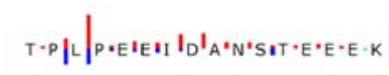

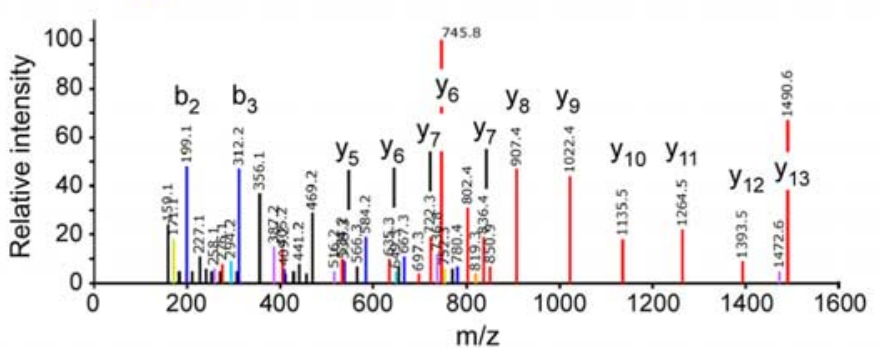

B

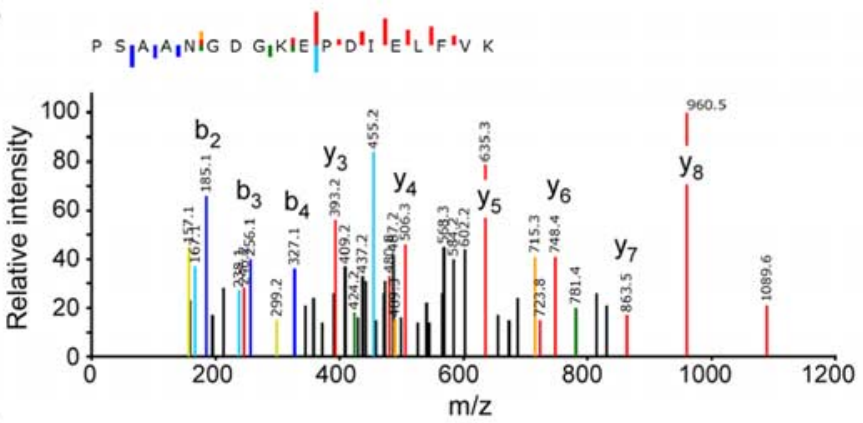

C

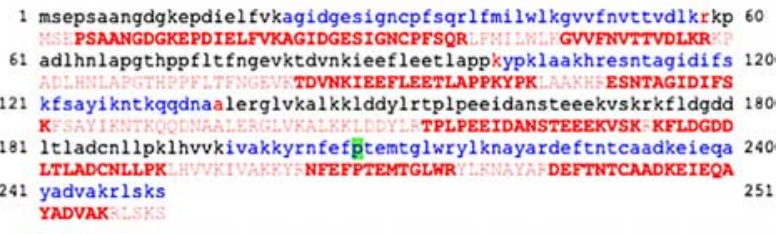

D

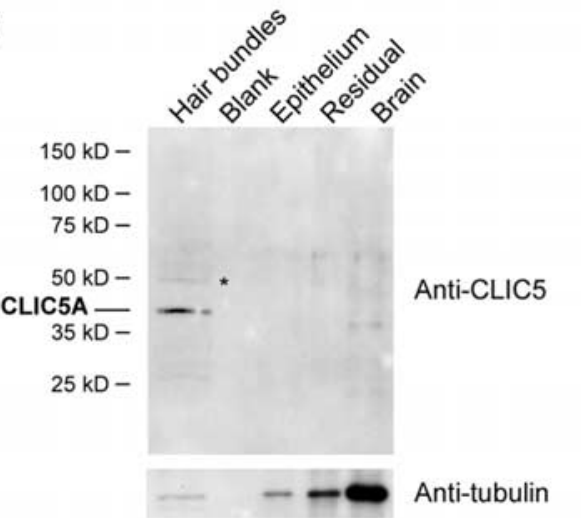

\section{E}
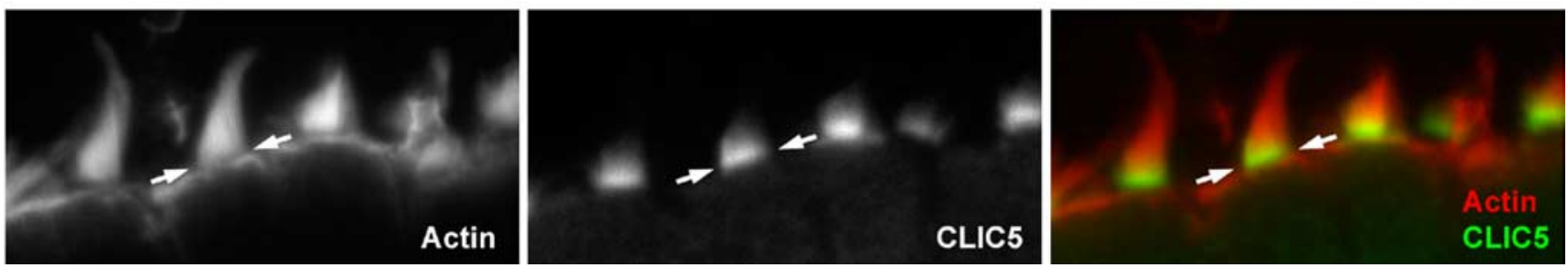

Figure 11. Identification of CLIC5A in purified chicken hair bundles. $A, B$, Graphical display of monoisotopic ion peak lists generated by Mascot Distiller software from tandem mass spectrometry data. Value indicated next to peak is mass-to-charge ( $\mathrm{m} / \mathrm{z}$ ) value. Positions of prominent $y$-ions (red) and b-ions (blue) are indicated. $\boldsymbol{A}$, Identification of TPLPEEIDANSTEEEK (residues 154 -169). $\boldsymbol{B}$, Identification of PSAANGDGKEPDIELFVK (residues 4-21), a peptide only found in CLIC5A. Note that, although the N-terminal cleavage was not tryptic, it was at an acid-labile Glu-Pro bond. Positions of y-ions (red) and b-ions (blue) are indicated. Other ions used in refinement were deamidated y-ions (orange), deamidated b-ions (green), and deoxidated b-ions (light blue). C, Coverage of CLIC5 protein sequence (57\%) in best mass spectrometry run. Lowercase lettering shows sequence with exons alternating in color. Bold red uppercase letters indicate sequences identified by mass spectrometry. D, Top, protein immunoblot detection of CLIC5A in isolated chicken hair bundles. Band corresponding to CLIC5A is indicated; a fainter, higher-molecular-mass band that could correspond to CLIC5B is also present (asterisk). Loading: 15 ear equivalents of hair bundles, 0.1 ear equivalents of sensory epithelium (Epithelium), 0.1 ear equivalents of utricular residue after scraping off sensory epithelium (Residual), and $\sim 3 \mu \mathrm{g}$ of brain protein (Brain). Bottom, Immunoblot of identical samples detected with anti-tubulin antibody. $E$, E18 chicken utricular hair bundles labeled with anti- $\beta$-actin (left) and anti-CLIC5 (middle); merged image is on right. Arrows indicate base of hair bundle at the apical surface; note that CLIC5 is predominately in the lower one-third of the bundle. Each panel has a horizontal width of $32 \mu \mathrm{m}$.

ment associated with CLIC5 deficiency. CLIC5 adds to a growing list of proteins that have been localized to stereocilia; identification of these constituents is crucial to understanding the mechanisms underlying hair bundle morphogenesis and maintenance.

\section{References}

Alagramam KN, Murcia CL, Kwon HY, Pawlowski KS, Wright CG, Woychik RP (2001) The mouse Ames waltzer hearing-loss mutant is caused by mutation of Pcdh15, a novel protocadherin gene. Nat Genet 27:99-102.

Anniko M, Virtanen I, Thornell LE (1987) Expression of intermediate filaments and actin in the embryonic human inner ear. Acta Otolaryngol Suppl 436:51-61.

Avraham KB, Hasson T, Steel KP, Kingsley DM, Russell LB, Mooseker MS, Copeland NG, Jenkins NA (1995) The mouse Snell's waltzer deafness gene encodes an unconventional myosin required for structural integrity of inner ear hair cells. Nat Genet 11:369-375.

Berry KL, Hobert O (2006) Mapping functional domains of chloride intracellular channel (CLIC) proteins in vivo. J Mol Biol 359:1316-1333.

Berry KL, Bulow HE, Hall DH, Hobert O (2003) A C. elegans CLIC-like protein required for intracellular tube formation and maintenance. Science 302:2134-2137.

Berryman M, Bretscher A (2000) Identification of a novel member of the chloride intracellular channel gene family (CLIC5) that associates with the actin cytoskeleton of placental microvilli. Mol Biol Cell 11:1509-1521.

Berryman M, Bruno J, Price J, Edwards JC (2004) CLIC-5A functions as a chloride channel in vitro and associates with the cortical actin cytoskeleton in vitro and in vivo. J Biol Chem 279:34794-34801.

Bretscher A, Reczek D, Berryman M (1997) Ezrin: a protein requiring conformational activation to link microfilaments to the plasma membrane in the assembly of cell surface structures. J Cell Sci 110:3011-3018.

Craig R, Beavis RC (2004) TANDEM: matching proteins with tandem mass spectra. Bioinformatics 20:1466-1467.

Craig R, Cortens JP, Beavis RC (2004) Open source system for analyzing, validating, and storing protein identification data. J Proteome Res 3:1234-1242.

Cromer BA, Morton CJ, Board PG, Parker MW (2002) From glutathione transferase to pore in a CLIC. Eur Biophys J 31:356-364.

Di Palma F, Holme RH, Bryda EC, Belyantseva IA, Pellegrino R, Kachar B, Steel KP, Noben-Trauth K (2001) Mutations in Cdh23, encoding a new type of cadherin, cause stereocilia disorganization in waltzer, the mouse model for Usher syndrome type 1D. Nat Genet 27:103-107.

Dixon MJ, Gazzard J, Chaudhry SS, Sampson N, Schulte BA, Steel KP (1999) Mutation of the Na-K-Cl co-transporter gene Slc12a2 results in deafness in mice. Hum Mol Genet 8:1579-1584. 
Domon B, Aebersold R (2006) Mass spectrometry and protein analysis. Science 312:212-217.

Dulhunty A, Gage P, Curtis S, Chelvanayagam G, Board P (2001) The glutathione transferase structural family includes a nuclear chloride channel and a ryanodine receptor calcium release channel modulator. J Biol Chem 276:3319-3323.

Edwalds-Gilbert G, Veraldi KL, Milcarek C (1997) Alternative poly(A) site selection in complex transcription units: means to an end? Nucleic Acids Res 25:2547-2561.

Everett LA, Belyantseva IA, Noben-Trauth K, Cantos R, Chen A, Thakkar SI, Hoogstraten-Miller SL, Kachar B, Wu DK, Green ED (2001) Targeted disruption of mouse Pds provides insight about the inner-ear defects encountered in Pendred syndrome. Hum Mol Genet 10:153-161.

Friedli M, Guipponi M, Bertrand S, Bertrand D, Neerman-Arbez M, Scott HS, Antonarakis SE, Reymond A (2003) Identification of a novel member of the CLIC family, CLIC6, mapping to 21q22.12. Gene 320:31-40.

Frolenkov GI, Belyantseva IA, Friedman TB, Griffith AJ (2004) Genetic insights into the morphogenesis of inner ear hair cells. Nat Rev Genet 5:489-498.

Gibson F, Walsh J, Mburu P, Varela A, Brown KA, Antonio M, Beisel KW, Steel KP, Brown SD (1995) A type VII myosin encoded by the mouse deafness gene shaker-1. Nature 374:62-64.

Gillespie PG, Hudspeth AJ (1991) High-purity isolation of bullfrog hair bundles and subcellular and topological localization of constituent proteins. J Cell Biol 112:625-640.

Griffon N, Jeanneteau F, Prieur F, Diaz J, Sokoloff P (2003) CLIC6, a member of the intracellular chloride channel family, interacts with dopamine D(2)-like receptors. Brain Res Mol Brain Res 117:47-57.

Harrop SJ, DeMaere MZ, Fairlie WD, Reztsova T, Valenzuela SM, Mazzanti M, Tonini R, Qiu MR, Jankova L, Warton K, Bauskin AR, Wu WM, Pankhurst S, Campbell TJ, Breit SN, Curmi PM (2001) Crystal structure of a soluble form of the intracellular chloride ion channel CLIC1 (NCC27) at 1.4-A resolution. J Biol Chem 276:44993-45000.

Johnson KR, Cook SA, Erway LC, Matthews AN, Sanford LP, Paradies NE, Friedman RA (1999) Inner ear and kidney anomalies caused by IAP insertion in an intron of the Eyal gene in a mouse model of BOR syndrome. Hum Mol Genet 8:645-653.

Johnson KR, Gagnon LH, Webb LS, Peters LL, Hawes NL, Chang B, Zheng QY (2003) Mouse models of USH1C and DFNB18: phenotypic and molecular analyses of two new spontaneous mutations of the Ush1c gene. Hum Mol Genet 12:3075-3086.

Kikkawa Y, Shitara H, Wakana S, Kohara Y, Takada T, Okamoto M, Taya C, Kamiya K, Yoshikawa Y, Tokano H, Kitamura K, Shimizu K, Wakabayashi Y, Shiroishi T, Kominami R, Yonekawa H (2003) Mutations in a new scaffold protein Sans cause deafness in Jackson shaker mice. Hum Mol Genet 12:453-461.

Kitajiri S, Fukumoto K, Hata M, Sasaki H, Katsuno T, Nakagawa T, Ito J, Tsukita S (2004) Radixin deficiency causes deafness associated with progressive degeneration of cochlear stereocilia. J Cell Biol 166:559-570.

LeMasurier M, Gillespie PG (2005) Hair-cell mechanotransduction and cochlear amplification. Neuron 48:403-415.

Littler DR, Assaad NN, Harrop SJ, Brown LJ, Pankhurst GJ, Luciani P, Aguilar MI, Mazzanti M, Berryman MA, Breit SN, Curmi PM (2005) Crystal structure of the soluble form of the redox-regulated chloride ion channel protein CLIC4. FEBS J 272:4996-5007.

Liu H, Sadygov RG, Yates III JR (2004) A model for random sampling and estimation of relative protein abundance in shotgun proteomics. Anal Chem 76:4193-4201.

Longo-Guess CM, Gagnon LH, Cook SA, Wu J, Zheng QY, Johnson KR (2005) A missense mutation in the previously undescribed gene Tmhs underlies deafness in hurry-scurry (hscy) mice. Proc Natl Acad Sci USA 102:7894-7899.

Mburu P, Mustapha M, Varela A, Weil D, El-Amraoui A, Holme RH, Rump A, Hardisty RE, Blanchard S, Coimbra RS, Perfettini I, Parkinson N, Mallon AM, Glenister P, Rogers MJ, Paige AJ, Moir L, Clay J, Rosenthal A, Liu XZ, Blanco G, Steel KP, Petit C, Brown SD (2003) Defects in whirlin, a PDZ domain molecule involved in stereocilia elongation, cause deafness in the whirler mouse and families with DFNB31. Nat Genet 34:421-428. Nishizawa T, Nagao T, Iwatsubo T, Forte JG, Urushidani T (2000) Molecu- lar cloning and characterization of a novel chloride intracellular channelrelated protein, parchorin, expressed in water-secreting cells. J Biol Chem 275:11164-11173.

Pataky F, Pironkova R, Hudspeth AJ (2004) Radixin is a constituent of stereocilia in hair cells. Proc Natl Acad Sci USA 101:2601-2606.

Petit C (2006) From deafness genes to hearing mechanisms: harmony and counterpoint. Trends Mol Med 12:57-64.

Probst FJ, Fridell RA, Raphael Y, Saunders TL, Wang A, Liang Y, Morell RJ, Touchman JW, Lyons RH, Noben-Trauth K, Friedman TB, Camper SA (1998) Correction of deafness in shaker-2 mice by an unconventional myosin in a BAC transgene. Science 280:1444-1447.

Proutski I, Karoulias N, Ashley RH (2002) Overexpressed chloride intracellular channel protein CLIC4 (p64H1) is an essential component of novel plasma membrane anion channels. Biochem Biophys Res Commun 297:317-322.

Redhead C, Sullivan SK, Koseki C, Fujiwara K, Edwards JC (1997) Subcellular distribution and targeting of the intracellular chloride channel p64. Mol Biol Cell 8:691-704.

Rezaul K, Wu L, Mayya V, Hwang SI, Han D (2005) A systematic characterization of mitochondrial proteome from human $\mathrm{T}$ leukemia cells. Mol Cell Proteomics 4:169-181.

Romand R, Zine AE, Hafidi A (1993) Ontogenesis of F-actin in hair cells. Cell Motil Cytoskeleton 25:213-222.

Saotome I, Curto M, McClatchey AI (2004) Ezrin is essential for epithelial organization and villus morphogenesis in the developing intestine. Dev Cell 6:855-864.

Self T, Mahony M, Fleming J, Walsh J, Brown SD, Steel KP (1998) Shaker-1 mutations reveal roles for myosin VIIA in both development and function of cochlear hair cells. Development 125:557-566.

Senften M, Schwander M, Kazmierczak P, Lillo C, Shin JB, Hasson T, Geleoc GS, Gillespie PG, Williams D, Holt JR, Muller U (2006) Physical and functional interaction between protocadherin 15 and myosin VIIa in mechanosensory hair cells. J Neurosci 26:2060-2071.

Shanks RA, Larocca MC, Berryman M, Edwards JC, Urushidani T, Navarre J, Goldenring JR (2002) AKAP350 at the Golgi apparatus. II. Association of AKAP350 with a novel chloride intracellular channel (CLIC) family member. J Biol Chem 277:40973-40980.

Suh KS, Mutoh M, Gerdes M, Crutchley JM, Mutoh T, Edwards LE, Dumont RA, Sodha P, Cheng C, Glick A, Yuspa SH (2005) Antisense suppression of the chloride intracellular channel family induces apoptosis, enhances tumor necrosis factor $\alpha$-induced apoptosis, and inhibits tumor growth. Cancer Res 65:562-571.

Taylor BA, Navin A, Phillips SJ (1994) PCR-amplification of simple sequence repeat variants from pooled DNA samples for rapidly mapping new mutations of the mouse. Genomics 21:626-632.

Tonini R, Ferroni A, Valenzuela SM, Warton K, Campbell TJ, Breit SN, Mazzanti M (2000) Functional characterization of the NCC27 nuclear protein in stable transfected CHO-K1 cells. FASEB J 14:1171-1178.

Truett GE, Heeger P, Mynatt RL, Truett AA, Walker JA, Warman ML (2000) Preparation of PCR-quality mouse genomic DNA with hot sodium hydroxide and tris (HotSHOT). Biotechniques 29:52, 54.

Tulk BM, Kapadia S, Edwards JC (2002) CLIC1 inserts from the aqueous phase into phospholipid membranes, where it functions as an anion channel. Am J Physiol Cell Physiol 282:C1103-C1112.

Warton K, Tonini R, Fairlie WD, Matthews JM, Valenzuela SM, Qiu MR, Wu WM, Pankhurst S, Bauskin AR, Harrop SJ, Campbell TJ, Curmi PM, Breit SN, Mazzanti M (2002) Recombinant CLIC1 (NCC27) assembles in lipid bilayers via a $\mathrm{pH}$-dependent two-state process to form chloride ion channels with identical characteristics to those observed in Chinese hamster ovary cells expressing CLIC1. J Biol Chem 277:26003-26011.

Washburn MP, Wolters D, Yates III JR (2001) Large-scale analysis of the yeast proteome by multidimensional protein identification technology. Nat Biotechnol 19:242-247.

Zheng L, Sekerkova G, Vranich K, Tilney LG, Mugnaini E, Bartles JR (2000) The deaf jerker mouse has a mutation in the gene encoding the espin actin-bundling proteins of hair cell stereocilia and lacks espins. Cell 102: 377-385.

Zheng QY, Johnson KR, Erway LC (1999) Assessment of hearing in 80 inbred strains of mice by ABR threshold analyses. Hear Res 130:94-107. 